\title{
Talc mediates angiostasis in malignant pleural effusions via endostatin induction
}

\author{
N. Najmunnisa*, K.A. Mohammed*, S. Brown\#, Y. Su*, P.S. Sriram*, B. Moudgil”, \\ R. Loddenkemper ${ }^{\oplus}$ and V.B. Antony*
}

ABSTRACT: Talc remains the most effective sclerosing agent for pleurodesis. However, its mechanism of action in resolving pleural malignant disease remains unclear.

The present study evaluated the angiogenic balance in the pleural space in patients with malignant pleural effusions (MPE) following talc insufflation.

Patient pleural fluid samples were collected both before and after talc insufflation. The ability of pleural mesothelial cells (PMC) and malignant mesothelioma cells (MMC) to produce endostatin in vitro was compared. The biological effects of pleural fluids and conditioned media from talcactivated PMC on endothelial cells were evaluated by performing proliferation, invasion, tube formation and apoptosis assays.

Pleural fluids from patients with MPE who received thoracoscopic talc insufflation contained significantly higher levels of endostatin (median $16.75 \mathrm{ng} \cdot \mathrm{mL}^{-1}$ ) compared with pre-talc instillation $\left(1.06 \mathrm{ng} \cdot \mathrm{mL}^{-1}\right)$. Talc-activated PMC released significantly greater amounts of endostatin (mean \pm SEM $1052.39 \pm 38.66 \mathrm{pg} \cdot \mathrm{mL}^{-1}$ ) when compared with a MMC line $\left(134.73 \pm 8.72 \mathrm{pg} \cdot \mathrm{mL}^{-1}\right)$.

In conlusion, talc alters the angiogenic balance in the pleural space from a biologically active and angiogenic environment to an angiostatic milieu. Functional improvement following talc poudrage in patients with malignant pleural effusions may, in part, reflect these alterations in the pleural space.

KEYWORDS: Angiogenesis, malignant pleural effusions, pleura, pleurodesis

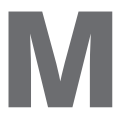

alignancy involving the pleura is the third leading cause of the development of pleural effusions [1, 2]. Approximately $50 \%$ of patients with metastatic cancer develop malignant pleural effusions (MPE). In the USA, >150,000 patients with MPE are diagnosed annually [3]. The presence of a malignant pleural effusion portends decreased survival and indicates that the tumour is surgically incurable. The quality of life is greatly diminished because of symptoms such as dyspnoea and cough [4]. Chemical pleurodesis via the instillation of a sclerosing agent into the pleural space is commonly employed in patients with recurrent MPE [5-7]. Pleurodesis with talc is the most commonly used method by chest physicians to prevent the symptomatic re-accumulation of pleural fluid (PF) in the pleural cavity of patients $[3,8,9]$. There are several reasons for choosing talc: it is more effective when compared with other sclerosing agents [911]; it is widely available and cheap; and it is

For editorial comments see page 619 . associated with minimal side-effects [12, 13]. However, recent concerns about adverse events have tempered its use [14, 15].

When talc is administered into the pleural space, it interacts with pleural mesothelial cells (PMC) leading to the development of an inflammatory response with the release of several cytokines and chemokines [16, 17]. The interactions between normal PMC and the tumour cells are largely unknown. However, the evidence from the present study suggests that PMC play a key role and may be critical in modulating the angiogenic environment in the pleural space of patients with MPE.

Endostatin, an inhibitor of angiogenesis, is released by normal cells and tissues. Endostatin is a $20-\mathrm{kDa}$ fragment of collagen XVIII that specifically inhibits endothelial cell migration, and induces cell cycle arrest, apoptosis, and reduces tumour growth [18]. The present authors recently reported that PMC release endostatin and invading tumour cells enhance the production of endostatin in PMCs [19]. In the present study, the authors hypothesise that talc induces PMC to release the anti-angiogenic factor, endostatin, and

\section{AFFILIATIONS}

*Division of Pulmonary and Critical Care Medicine, Dept of Medicine, College of Medicine, and \#Dept of Materials Science and Engineering, College of Engineering, and Particle Engineering Research Center, University of Florida, Gainesville, FL, USA.

"Lungenklinik Heckeshorn, Berlin, Germany.

CORRESPONDENCE

V.B. Antony

Division of Pulmonary and Critical

Care Medicine

Dept of Medicine

University of Florida

P.0. Box 100225

Gainesville

$\mathrm{FL}$

USA

Fax: 13522714559

E-mail: antonvb@medicine.ufl.edu

Received:

May 082006

Accepted after revision:

December 262006

SUPPORT STATEMENT

This work was supported in part by grants NIH R01 A145338-02 and NIH R01 A141877-04 from the National Institute of Health.

STATEMENT OF INTEREST None declared. 
that this may modulate malignant growth on the pleura by tilting the pro-angiogenic environment of the pleural space to an anti-angiogenic milieu.

\section{MATERIAL AND METHODS}

\section{Cell culture}

Human PMC in primary culture (Clonetics Corp., San Diego, CA, USA) between four and eight passages were used. The cells were cultured in Ham's-199 culture medium (Gibco Laboratories, Grand Island, NY, USA) containing 10\% foetal bovine serum (FBS; Atlanta Biologicals, Lawrenceville, GA, USA), as reported previously [16]. The malignant mesothelioma cell line (MMC), CRL-2081, was obtained from ATCC (Rockville, MD, USA) and cultured in RPMI 1640 media with 10\% FBS [20]. Primary human umbilical vein endothelial cells (HUVEC) were obtained from Cell Applications, Inc. (San Diego, CA, USA). The endothelial cells were cultured according to the manufacturer's instructions. In brief, the HUVEC were grown in growth medium purchased from Cell
Applications Inc., in a T-75 flask. The media was changed on alternate days and the cells were subcultured when HUVEC reached $60-80 \%$ confluence. Cells between four and eight passages were used for all assays.

\section{Characterisation of talc}

Talc $\left(3 \mathrm{MgO} .4 \mathrm{SiO}_{2} \cdot \mathrm{H}_{2} \mathrm{O}\right.$; Bryan Corporation, Woburn, MA, USA) is a tri-layered mineral compound that primarily consists of pulverised hydrous magnesium silicate. The particle size, surface area and crystalline impurity data are provided to enable future comparisons with this study.

\section{Particle size analysis}

Talc particle dispersions were prepared in de-ionised water and measured on a Coulter LS 13320 Particle Size Analyzer (Beckman-Coulter Inc., Miami, FL, USA), utilising the small liquid volume module and both laser diffraction and the polarised intensity differential scattering techniques. The particle size distributions given in figure 1c were found to be
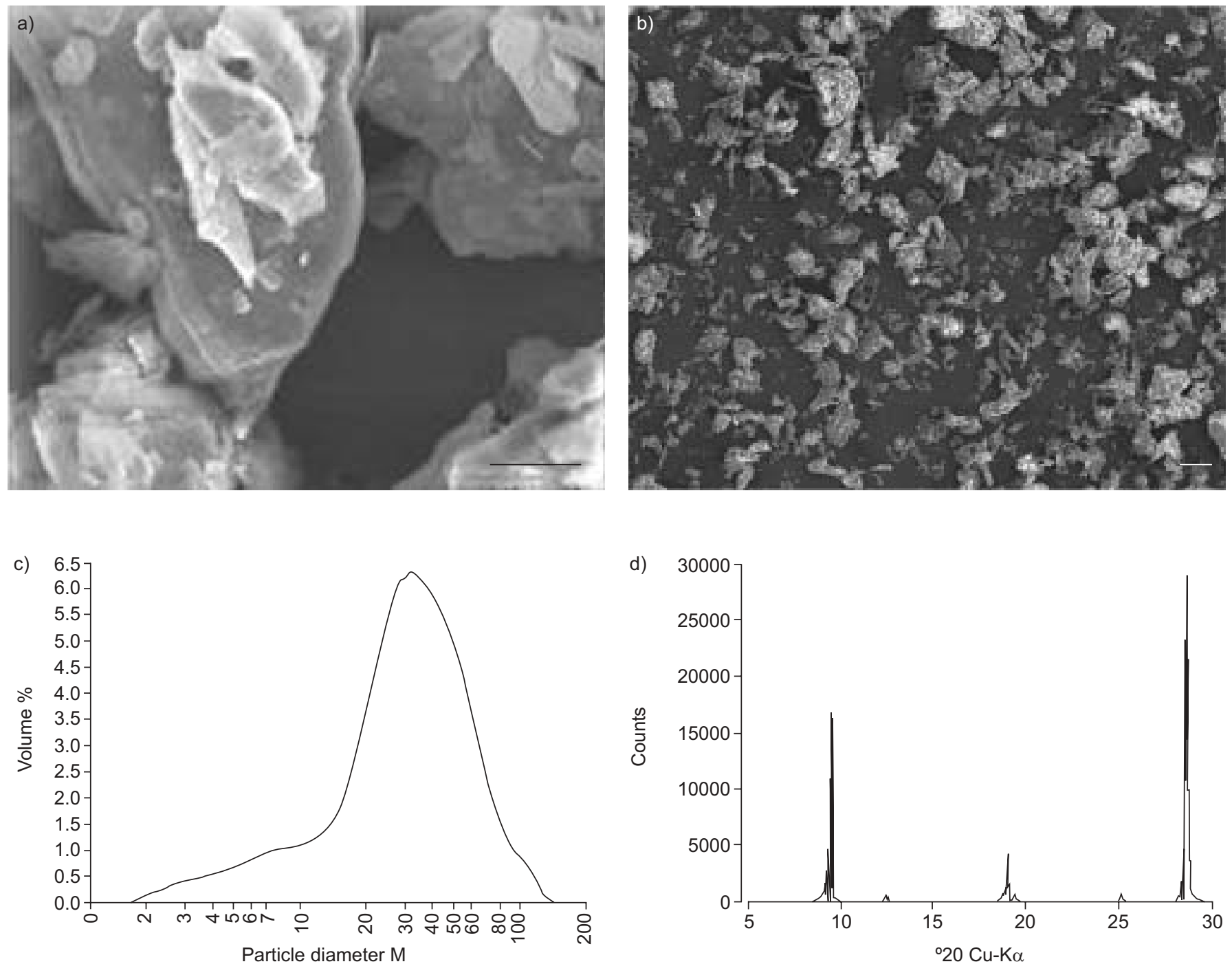

FIGURE 1. $a$ and b) Scanning electron micrographs of the talc used in the present study deposited on a silicon wafer. Scale bars $=1 \mu \mathrm{m}$ (a) and $100 \mu \mathrm{m}$ (b). c) Particle size distribution against volume. d) Representative X-ray diffraction pattern for the talc powder used in the current study; the diffraction pattern is the indication of talc peaks. 
comparable with values obtained with field emission scanning electron microscopy images (JSM6330F; JEOL Ltd, Tokyo, Japan).

\section{Surface area analysis}

The specific surface area of the talc powder was measured to be mean \pm SEM $1.90 \pm 0.02 \mathrm{~m}^{2} \cdot \mathrm{g}^{-1}$ by the physisorption of krypton gas $(\mathrm{Kr})$ using the method of BRUNAUER et al. [21] with a Quantachrome Autosorb 1C-MS apparatus (Quantochrome Corp., Boyton Beach, FL, USA). Gas adsorption on solid surfaces is commonly used to obtain the specific surface area and pore size distribution of powdered materials. Essentially, a dry sample is usually evacuated of all gas and cooled to a temperature of $77 \mathrm{~K}$, the temperature of liquid nitrogen. At this temperature, inert gases such as nitrogen, argon and krypton will physically adsorb on the surface of the sample. The adsorption process of molecules onto the surface is measured by monitoring a change in pressure, which is then used to determine the number of molecules adsorbed and from this the surface area is determined. $\mathrm{Kr}$ adsorption at $77 \mathrm{~K}$ is a much more sensitive technique compared to conventional methods using nitrogen.

\section{X-ray diffraction analysis}

A paste was prepared from talc with a 7:1 mixture of amyl acetate and colloidan, and then applied to a glass slide. The sample was air dried prior to measurement. X-ray diffraction patterns were obtained on a Phillips APD 3700 Powder X-ray Diffractometer (PANalytical B.V., Almelo, the Netherlands) with cobalt/nickel-filtered copper- $\mathrm{K} \alpha$ radiation $(40 \mathrm{kV}$, $20 \mathrm{~mA}$ ).

\section{Talc particle preparation}

Talc particles are suspended in endotoxin-free $0.89 \%$ normal saline at a concentration of $10 \mathrm{mg} \cdot \mathrm{mL}^{-1}$. The particles are washed and then autoclave sterilised. The stock samples of talc had undetectable levels of endotoxin as determined by limulus amebocyte lysate assay (Sigma Chemical, St Louis, MO, USA). Talc samples were dispersed in pH 5.8 Nanopure DI (Barnstead Thermolyne, Dubuque, IA, USA) water by vortexing. The agitation time and energy was carefully chosen to ensure maximum de-aggregation and no milling of the talc particles.

\section{Activation of PMC and MMC with talc}

PMC and MMC were treated with varying concentrations of talc $\left(0,10,25,50,100\right.$ and $\left.200 \mu \mathrm{g} \cdot \mathrm{cm}^{-2}\right)$ and incubated for $24 \mathrm{~h}$ at $37^{\circ} \mathrm{C}$ in $5 \%$ carbon dioxide and $95 \%$ air. The cell culture supernatants were collected after $24 \mathrm{~h}$. The collected supernatants were liquated and stored at $-70^{\circ} \mathrm{C}$ for further use. The viability of the PMC was assessed by a Trypan-blue dye exclusion assay.

\section{Patient study}

A total of 16 patients at the Lugenklinik Heckeshorn (Berlin, Germany) who had symptomatic MPE and achieved successful pleurodesis were studied. Pleurodesis was termed successful when the pleural effusion did not recur at any time during follow-up until the death of the patient. Of the 16 patients, nine were female and seven male; seven patients had lung cancer, five had breast cancer and four had mesothelioma. The mean \pm SEM age group of the patients included in the present study was $64.2 \pm 12.6$ yrs (range $42-88 \mathrm{yrs}$ ). All patients in the study gave informed consent, and the study was performed in accordance with the Lugenklinik Heckenshorn institutional review board guidelines. Patients in whom malignant pleural effusions were diagnosed by pleural cytology and who fulfilled the American Thoracic Society/European Respiratory Society guidelines for the management of pleural effusions were included for the study. Medical thoracoscopy was performed under local anaesthesia.

\section{Collection of PF}

PF was obtained via thoracentesis, as previously described [22], from patients with symptomatic malignant pleural effusions $(n=16)$ according to a protocol approved by the institutional review board. During thoracoscopy, following the removal of $\mathrm{PF}, 2-4 \mathrm{~g}$ of sterile, asbestos-free, lipopolysaccharide-free talc was instilled by insufflation (poudrage) into the pleural cavity under visual control to ensure homogeneous distribution. On completion of the procedure, a chest tube was left in place in all patients. The total amount of PF drainage from the chest tube in patients who responded to the procedure was $<200 \mathrm{~mL}$ following talc insufflation. The chest tube was removed once the output dropped below $150 \mathrm{cc} \cdot 24 \mathrm{~h}^{-1}$. PF was obtained at the beginning of thoracoscopy (baseline), immediately after thoracoscopy, and at 4- and 24-h postthoracoscopy. All samples were centrifuged and the supernatants were aliquoted into $2-\mathrm{mL}$ samples and frozen at $-70^{\circ} \mathrm{C}$ until further tests were performed.

\section{Estimation of endostatin by ELISA}

Endostatin levels in the PF $(0,4$ and $24 \mathrm{~h})$ and culture medium obtained from activated PMC and $\operatorname{MMC}(0,10,25,50,100$ and $200 \mu \mathrm{g} \cdot \mathrm{cm}^{-2}$ ) and resting PMC and MMC were quantified using a sandwich enzyme immunoassay kit (Chemicon International, Inc., Temecula, CA, USA) as previously described elsewhere [19].

\section{5-bromo-2'-deoxyuridine cell proliferation assay}

Primary HUVEC were treated with PF obtained from patients with MPE before and after thoracoscopic talc insufflation and condition medium (CM) from talc-activated PMC or resting $\mathrm{PMC}$ and incubated for $24 \mathrm{~h}$ at $37^{\circ} \mathrm{C}$. Cell proliferation was assessed by a colorimetric assay kit according to the manufacturer's instructions (Calbiochem, San Diego, CA, USA).

\section{Invasion assay}

In vitro invasion assays were carried out using the BD Biocoat Angiogenesis System (BD Biosciences, Bedford, MA, USA) according to the manufacturer's protocols. Briefly, HUVEC $\left(1 \times 10^{5}\right.$ cells $)$ in suspension were seeded on BD Biocoat Matrigel (BD Biosciences) 24-well culture plates in the absence (control) and presence of PF and CM from resting and talcactivated PMC. The lower chamber contained the chemoattractant. After $16 \mathrm{~h}$, the migrated cells were labelled with calcein acetoxymethyl ester and the fluorescence intensity was recorded at $450 \mathrm{~nm}$ using a fluorescence plate reader (Cytofluor; Applied biosciences, Gaithersburg, MD, USA). Data are expressed as a per cent invasion of HUVEC over control. 


\section{Capillary-like tube formation assay}

A tube formation assay was performed as previously desribed [23]. Briefly, a 96-well culture plate was coated with $100 \mu \mathrm{L}$ of matrigel per well and allowed to polymerise for $30 \mathrm{~min}$ at $37^{\circ} \mathrm{C}$. HUVEC at a density of $3 \times 10^{4}$ cells $^{\prime}$ well $^{-1}$ were plated in $0.3 \mathrm{~mL}$ of serum-free RPMI 1640 media. The cells were pretreated with $\mathrm{PF}$ and $\mathrm{CM}$ from talc-activated PMC and resting PMC for $1 \mathrm{~h}$ at $37^{\circ} \mathrm{C}$. The cells were placed on matrigel, after a 10-h incubation, four to six randomly chosen fields (at $10 \times$ magnification) from the sample were photographed, and total tube areas were analysed by the Axio-vision image programme (Carl Zeiss, Houston, TX, USA).

\section{Annexin-V fluoroscein isothiocyanate and propidium iodide staining}

HUVEC at $80 \%$ confluence were pretreated with PF and CM from talc-activated PMC and resting PMC. After $48 \mathrm{~h}$, detached cells in the medium were collected and the remaining adherent cells were harvested by trypsinisation. The cells $\left(1 \times 10^{5}\right)$ were washed with PBS and resuspended in $250 \mu \mathrm{L}$ of binding buffer (annexin-V fluoroscein isothiocyanate (FITC) kit; Becton Dickinson, Franklin Lakes, NJ, USA) containing $10 \mu \mathrm{L}$ of $20 \mu \mathrm{g} \cdot \mathrm{mL}^{-1}$ propidium iodide (PI) and $5 \mu \mathrm{L}$ of annexin- $V$ FITC. After incubation for $10 \mathrm{~min}$ at room temperature in a light-protected area, the samples were analysed on a FACSCalibur flow cytometer (Becton Dickinson). FITC and PI emissions were detected in the FL-1 and FL-2 channels, respectively. Subsequent analysis was carried out using with CellQuest software (Becton Dickinson).

\section{Statistical methods}

Statistical differences between experimental groups were tested using ANOVA. The Kruskal-Wallis test was used for analysis of differences between more than two groups and the Mann-Whitney U-test was used for analysis between two specific groups. Data were considered significant if $\mathrm{p}<0.05$.

\section{RESULTS}

\section{X-ray diffraction crystallography}

In order to provide more detailed information of the talc used in this study, X-ray diffraction was used to provide the crystalline fingerprint analysis of talc. A scanning electron micrograph of talc is shown as figure 1a. Figure 1d represents a characteristic X-ray diffractrogram from the talc used in the present study.

\section{PF from patients with MPE contains endostatin}

$\mathrm{PF}$ endostatin was measured sequentially before and after talc pleurodesis. The PFs were collected at 0,4 and $24 \mathrm{~h}$ after the procedure. Endostatin levels were found to be significantly higher in all MPE collected at $24 \mathrm{~h}$. Following talc insufflation, the statistical difference among groups was not significant $(p=0.194)$ when comparing lung cancer (median (interquartile range) 17.55 (11.96-21.49) $\left.\mathrm{ng} \cdot \mathrm{mL}^{-1}\right)$; breast cancer $(15.26$ $\left.(10.66-20.26) \mathrm{ng} \cdot \mathrm{mL}^{-1}\right)$ and malignant mesothelioma (18.42 $\left.(15.81-20.12) \mathrm{ng} \cdot \mathrm{mL}^{-1}\right)$ patients, with breast cancer $(1.05(0.7-$ 1.50) $\left.\mathrm{ng} \cdot \mathrm{mL}^{-1}\right)$ and malignant mesothelioma (1.55 (1.122.2) $\left.\mathrm{ng} \cdot \mathrm{mL}^{-1}\right)$ patients at $0 \mathrm{~h} \mathrm{PF}\left(1.5(1.0-1.67) \mathrm{ng} \cdot \mathrm{mL}^{-1}\right)$. The $0 \mathrm{~h}$ (before insufflation of talc) sample was considered as control. The data are presented in figure 2 as box plots showing upper and lower quartile ranges.

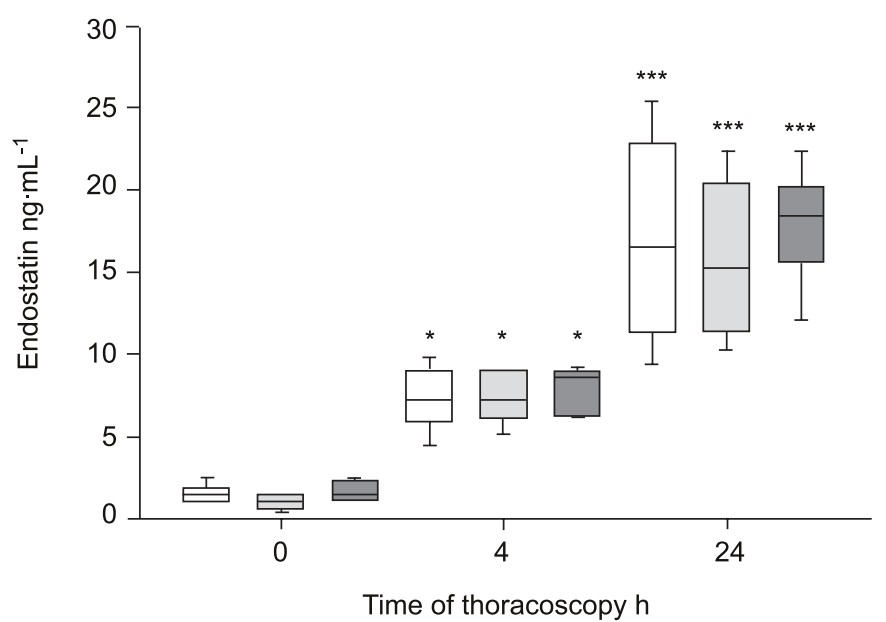

FIGURE 2. Pleural fluid endostatin levels over time. Endostatin levels were measured in the pleural fluids of lung cancer $(\square)$, breast cancer $(\square)$ and malignant mesothelioma ( $\square$ ) patients with malignant pleural effusions prior to $(0 \mathrm{~h})$ and post ( 4 and $24 \mathrm{~h}$ ) thoracoscopy. Boxes represent the median \pm interquartile range and bars represent upper and lower quartile ranges. $*$ : $p<0.05$ versus $0 h$; $* * *$ : $p<0.001$ versus $0 h$.

\section{Talc-activated PMC release endostatin}

PMC and MMC were treated with various concentrations of talc $\left(0,10,25,50,100\right.$ and $\left.200 \mu \mathrm{g} \cdot \mathrm{cm}^{-2}\right)$ and incubated for $24 \mathrm{~h}$ at $37^{\circ} \mathrm{C}$. The culture supernatants were collected after $24 \mathrm{~h}$. PMC activated with talc at a concentration of $25 \mu \mathrm{g} \cdot \mathrm{cm}^{-2}$ released significantly higher levels of endostatin (mean \pm SEM $\left.1052.39 \pm 38.66 \mathrm{pg} \cdot \mathrm{mL}^{-1} ; \mathrm{p}<0.001\right)$ when compared with MMC $\left(134.73 \pm 8.72 \mathrm{pg} \cdot \mathrm{mL}^{-1}\right)$. MMC produced minimal levels of endostatin at all concentrations tested (fig. 3). However, with increasing concentrations of talc the endostatin levels significantly decreased in PMC. These data indicate that at higher doses, talc has an inhibitory effect on PMC endostatin production, and thus affects the biological activity of the cells.

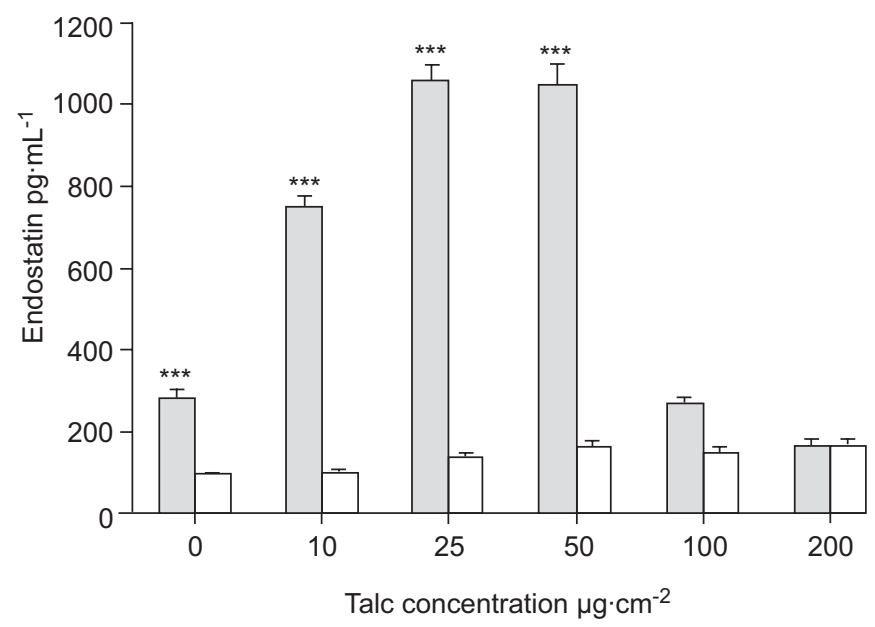

FIGURE 3. Talc-induced endostatin release in pleural mesothelial cells (PMC; - ) and malignant mesothelioma cells (MMC; $\square$ ). PMC and MMC were activated with varying concentrations of talc $\left(0-200 \mu \mathrm{g} \cdot \mathrm{cm}^{-2}\right)$ for $24 \mathrm{~h}$ and the endostatin released was measured. Data are expressed as the mean \pm SEM of four independent experiments. ${ }^{* * *}: p<0.001$ versus MMC. 


\begin{tabular}{ll} 
TABLE $\mathbf{1}$ & $\begin{array}{l}\text { The percentage viability of pleural mesothelial } \\
\text { cells exposed to various concentrations of talc } \\
\text { as evaluated by Trypan-blue dye exclusion }\end{array}$ \\
& \\
\hline Talc $\mathbf{\mu} \cdot \mathbf{c} \cdot \mathbf{c m}^{-\mathbf{2}}$ & \\
\hline $\mathbf{0}$ & $98.8 \pm 3.8$ \\
$\mathbf{1 0}$ & $97.6 \pm 4.3$ \\
$\mathbf{2 5}$ & $97.2 \pm 3.5$ \\
$\mathbf{5 0}$ & $96.4 \pm 5.2$ \\
$\mathbf{1 0 0}$ & $91.8 \pm 7.5$ \\
$\mathbf{2 0 0}$ & $87.5 \pm 9.3$ \\
\hline
\end{tabular}

Data are presented as the mean \pm SEM of six individual experiments.

In order to evaluate whether higher doses of talc have any cytotoxic effect on PMC, the PMC viability was estimated with a Trypan-blue dye exclusion assay on PMC activated with various concentrations of talc; the data are presented in table 1.

\section{Talc alters the angiogenic activity (as measured by} proliferation, invasion and tube formation of HUVEC) in PF from patients who receive talc insufflation

The endothelial cells were pretreated with PF obtained from patients with malignant pleural effusions post-thoracoscopy at 0,4 and $24 \mathrm{~h}$. The following components of angiogenesis were evaluated.

1) The proliferative capacity of the cells was determined by 5 bromo-2'-deoxyuridine (BrdU) cell proliferation assay (fig. 4a). $\mathrm{PF}$ collected $24 \mathrm{~h}$ post talc insufflation significantly decreased the proliferation of HUVEC $(42.96 \pm 3.18 \%)$ compared with PF prior to talc insufflation. Culture supernatant obtained from talc activated PMC significantly inhibited the proliferation of HUVEC $(33.06 \pm 4.64 \%)$ compared with PMC-CM

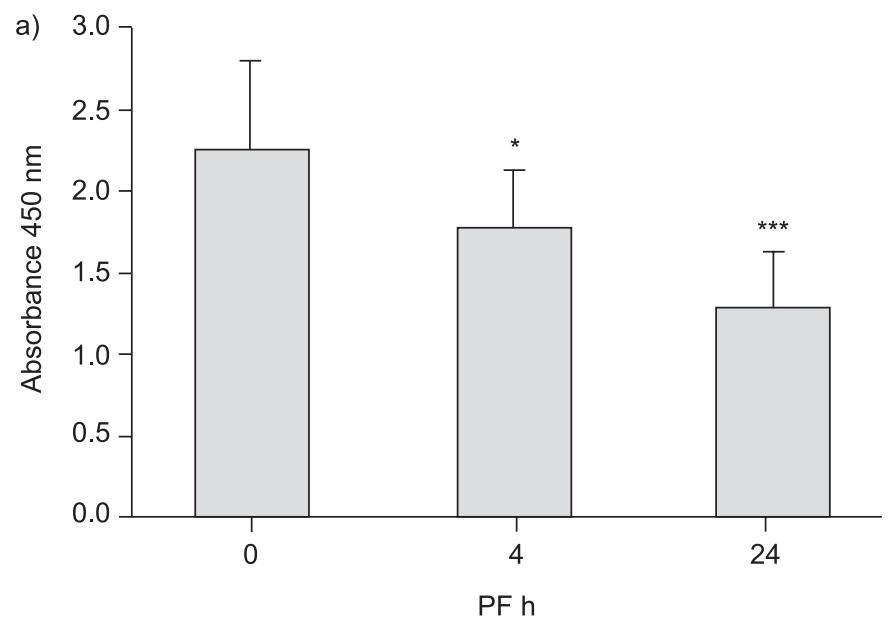

$(18.61 \pm 2.64 \%)$. Addition of anti-human endostatin antibody inhibited the anti-proliferative effect and the proliferation of HUVEC was enhanced significantly (fig. 4b).

2) Endothelial cell invasion and tube formation were evaluated in matrigel in order to evaluate the biological activity of PF and $\mathrm{CM}$ of talc-activated PMC. The invasion of endothelial cells was significantly inhibited in the PF samples obtained from $24 \mathrm{~h}$ post talc insufflation when compared with the $0 \mathrm{~h}$ control $(24.25 \pm 3.85 \% ; \mathrm{p}<0.05)$ against the chemoattractant vascular endothelial growth factor (VEGF; fig. 5a). There was an $18.84 \pm 2.28 \%(\mathrm{p}<0.05)$ and $10.49 \pm 1.21 \%$ inhibition of invasion of endothelial cells in the samples treated with culture supernatants of talc-activated and resting PMC, respectively (fig. 5b).

3) Tube formation of endothelial cells was significantly disrupted in samples treated with PF from patients $24 \mathrm{~h}$ post talc insufflation. A mean \pm SEM decrease of $52.58 \pm 6.64 \%$ in tube length formation was noticed compared with the $0 \mathrm{~h}$ PF sample (fig. 6). The tube-like structure formation of endothelial cells was also disrupted, and a significant decrease in the tube length was noticed in the samples treated with culture supernatants of talc-activated $\left(25 \mu \mathrm{g} \cdot \mathrm{cm}^{2}\right)$ PMC compared with resting PMC $(23.84 \pm 3.64 \% ; \mathrm{p}<0.05)$, suggesting the release of an anti-angiogenic factor (fig. 7).

\section{PF collected post thoracoscopy and conditioned medium from talc-activated PMC induces apoptosis in HUVEC}

An early step in the process of cell death is the redistribution of phosphatidylserine (PS) from the inner leaflet to the outer leaflet of the plasma membrane, due to the loss of membrane asymmetry [24]. The externalised PS can be visualised by incubating intact cells with a fluorescent derivative of the protein annexin- $\mathrm{V}$, a phospholipid-binding protein. PI is a fluorochrome used to label DNA. Annexin-V FITC staining was performed in order to determine the apoptosis of HUVEC

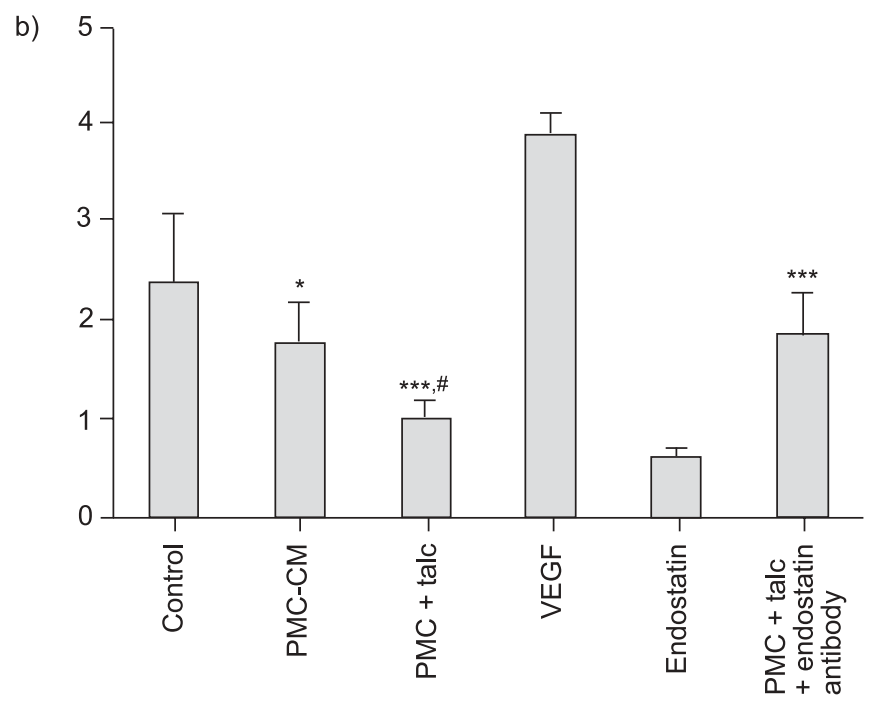

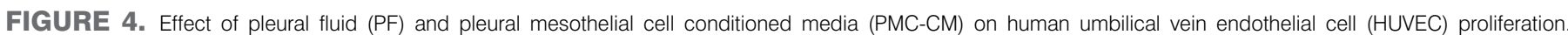

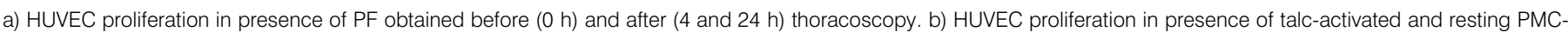

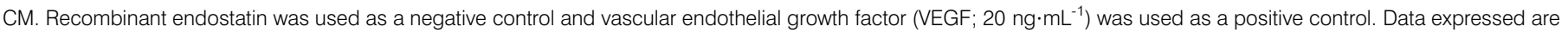

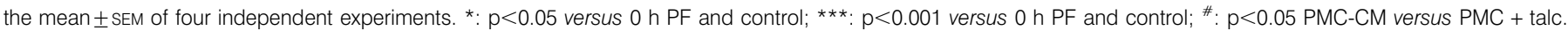



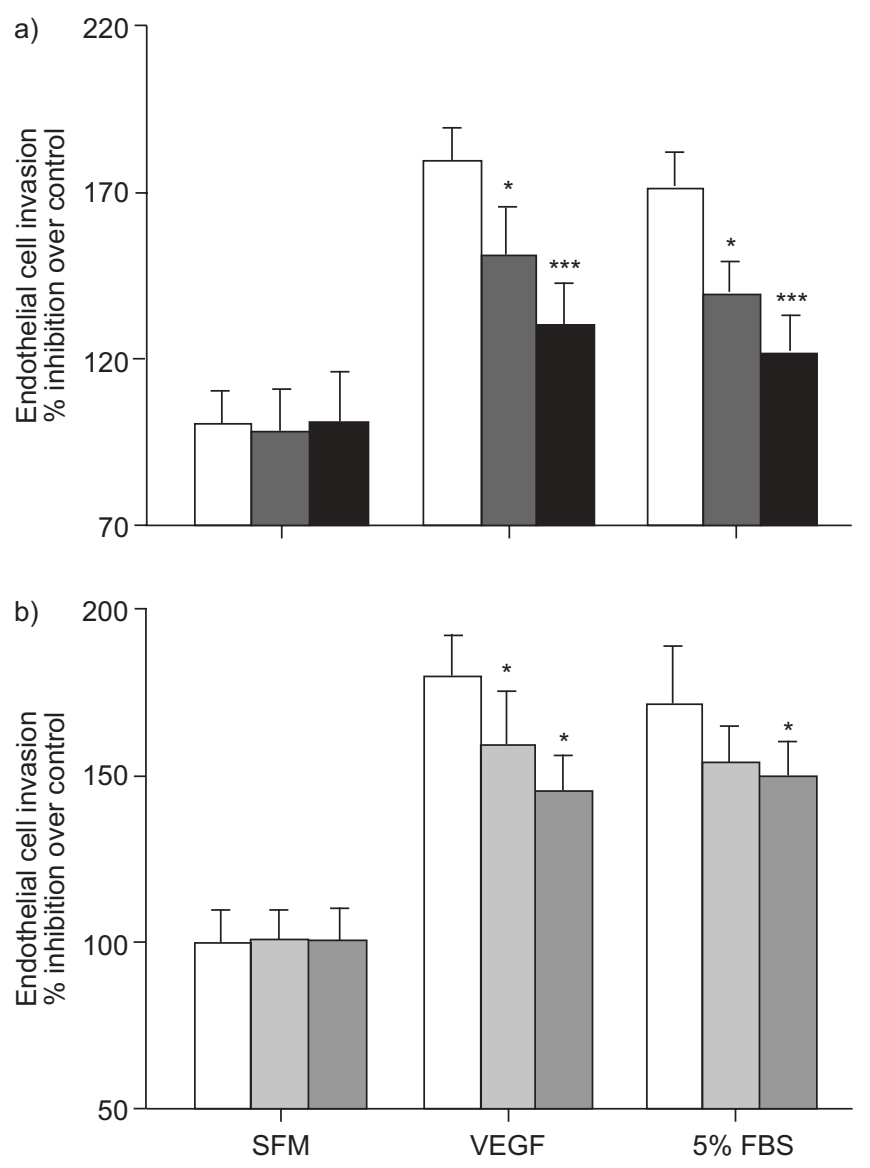

Chemoattractant

FIGURE 5. Effect of pleural fluid (PF) and pleural mesothelial cell conditioned media (PMC-CM) on human umbilical vein endothelial cell (HUVEC) invasion. a) HUVEC invasion after pre-treatment with pleural fluids obtained before (control, $0 \mathrm{~h} ; \square$ ) and after (4 h: $\square$; and $24 \mathrm{~h}: \mathbf{\square}$ ) thoracoscopy. b) HUVEC invasion in control and after pre-treatment with talc-activated $(\square)$ and resting $(\square)$ PMC-CM. Data are expressed as \% HUVEC invasion over control against chemoattractants. SFM: serum-free media; VEGF: vascular endothelial growth factor; FBS: foetal bovine serum. *: $p<0.05 ;{ }^{* * *}: p<0.001$ versus $0 \mathrm{~h} \mathrm{PF}$ and control.

induced by PF or culture supernatants obtained from resting PMC and talc-activated PMC. The apoptosis was noticed in HUVEC cultured in the PF samples obtained $24 \mathrm{~h}$ post talc insufflation when compared with the $0 \mathrm{~h}$ control (mean \pm SEM $31.24 \pm 2.85 \%$ versus $7.89 \pm 2.85 \%$; $<<0.05$ ). The $4 \mathrm{~h}$ PF showed $12.68 \pm 2.27 \%$ apoptosis of HUVEC (data not shown). Approximately $21.86 \pm 2.68 \% \quad(\mathrm{p}<0.05)$ and $18.68 \pm 2.21 \%$ $(\mathrm{p}<0.05)$ apoptosis was observed in the samples treated with culture supernatants of talc-activated and resting PMC, respectively. Actinomycin-D was used as a positive control (fig. 8).

\section{DISCUSSION}

Lung, breast and ovarian cancers account for 50-65\% of MPE. Life expectancy following the diagnosis of a MPE is usually $<6$ months. Talc has been widely used for pleurodesis in patients with MPE. Talc is known to induce apoptosis in malignant cells and to improve survival and quality of life in
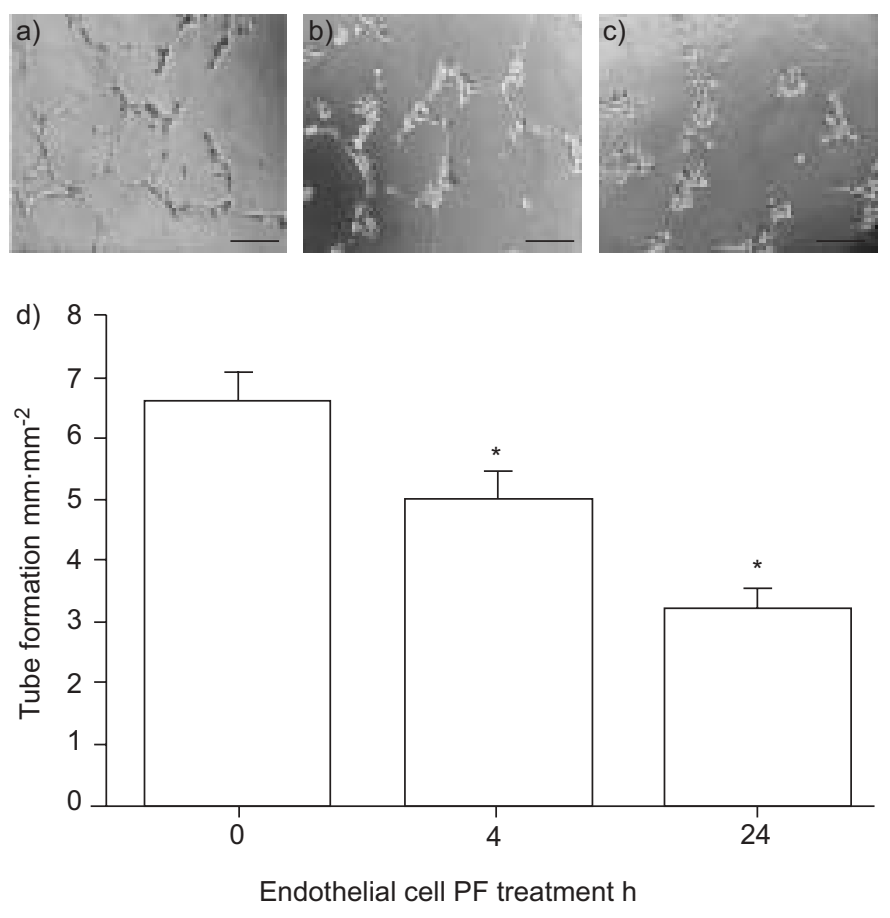

FIGURE 6. Effect of pleural fluid (PF) on tube formation in human umbilical vein endothelial cells (HUVEC). A representative image of tube formation in HUVEC in the presence of PF obtained from patients a) before ( $0 \mathrm{~h})$ and after b) $4 \mathrm{~h}$ and c) $24 \mathrm{~h}$ talc thoracoscopy. d) Tube formation $\left(\mathrm{mm} \cdot \mathrm{mm}^{-2}\right)$ in HUVEC. Data presented are the mean \pm SEM of three separate experiments. ${ }^{*}: \mathrm{p}<0.05$ versus $0 \mathrm{~h}$ PF.

those who have had successful pleurodesis [4, 20, 24, 25]. The present study demonstrates that talc induces PMCs to release the anti-angiogenic factor, endostatin, which may be responsible for containment of tumour growth in the pleural space and may account, in part, for the improved clinical status of patients who have had successful pleurodesis.

Although talc is by far the most effective sclerosing agent, with a success rate $>90 \%$, its use remains controversial [5, 26-28]. The quality of talc, including the particle size and dose used for pleurodesis, has shown varied effects on the morbidity of the patients with malignant MPE. The present authors believe that the magnitude of adverse effects is greater when the particle size is $<10 \mu \mathrm{m}[12,29,30]$, compared with graded talc with the smallest particles removed [31]. Moreover, most of the reported cases of lung injury and acute respiratory distress syndrome have been associated with a high talc dose [12, 29]. The talc used in the current study was characterised, providing information on size and crystalline finger print analysis. This analysis can be important when exposing in vitro cultures of cells to talc particulates, as well as for studies carried out on clinical samples from patients treated with talc.

Angiogenesis is critical for tumour growth as well as the establishment of metastatic deposits. Malignant cells release several angiogenic factors that promote new blood vessel formation and tumour growth [32-35]. The present authors have previously demonstrated that cancer cells induce PMC to release VEGF [32]. However, a normal mesothelium is critical in maintaining the dynamic balance of angiogenic versus antiangiogenic factors $[19,32]$. The present authors' model clearly 

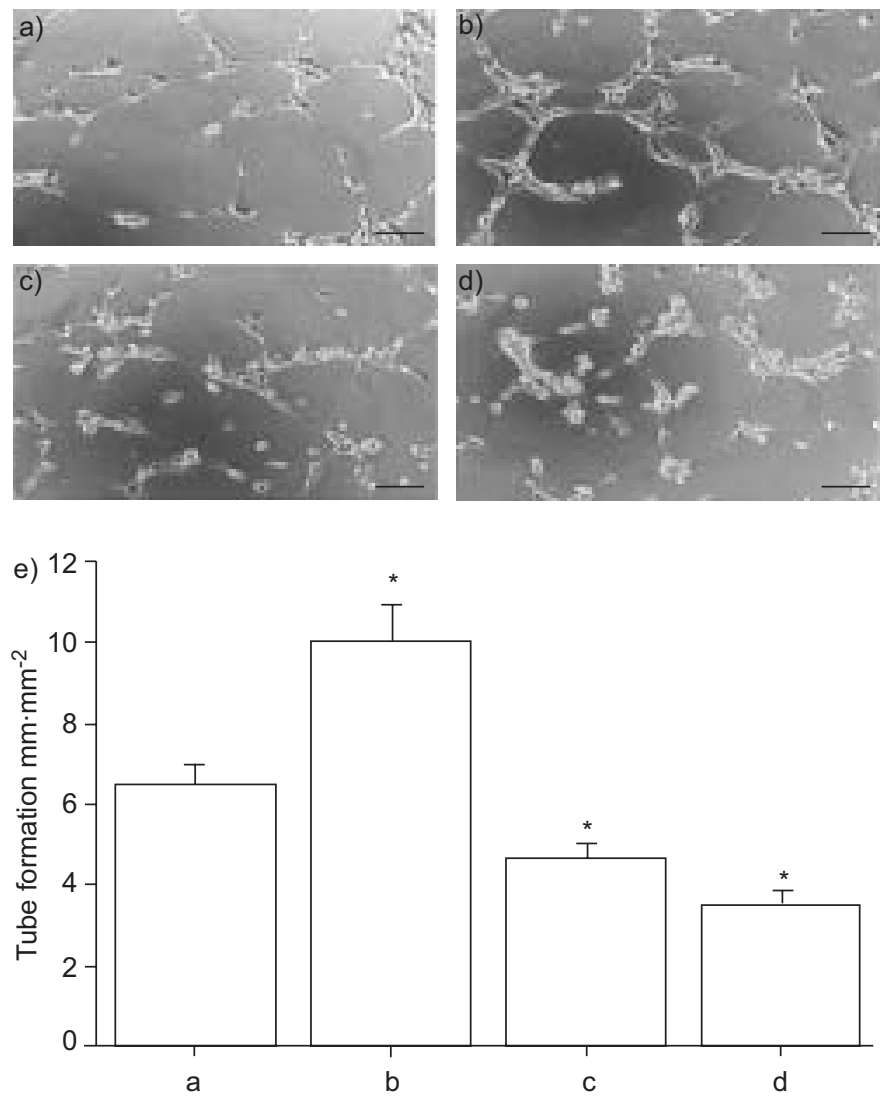

Endothelial cell treatment

FIGURE 7. Effect of pleural mesothelial cell conditioned media (PMC-CM) on tube formation in human umbilical vein endothelial cells (HUVEC). A representative image of tube formation in HUVEC exposed to CM obtained from a) control pleural mesothelial cells (PMC), b) vascular endothelial growth factor (VEGF; $20 \mathrm{ng} \cdot \mathrm{mL}^{-1}$ ), c) PMC + talc $\left(10 \mu \mathrm{g} \cdot \mathrm{cm}^{-2}\right)$ and d) PMC + talc $\left(25 \mu \mathrm{g} \cdot \mathrm{cm}^{-2}\right)$. e) Tube formation measured in $\mathrm{mm} \cdot \mathrm{mm}^{-2}$. Data presented are the mean \pm SEM of three separate experiments. *: $p<0.05$ versus control PMC.

demonstrate that malignant cells growing on the pleural surface gain metastatic potential by inducing the production of VEGF, thus creating a pro-angiogenic milieu in the pleural space [32].

RUIZ et al. [36] reported that angiogenic activators were higher in neoplastic pleural effusions than nonmalignant effusions. However, no significant difference in endostatin levels was noticed. The present study demonstrates that PF obtained from patients with MPE who undergo thoracoscopic talc insufflation contain significantly higher levels of endostatin when compared with PFs from patients who have not received intrapleural talc. Lower levels of endostatin in PF before talc insufflation is consistent with the current authors' hypothesis that the PF in MPE is predominantly pro-angiogenic. Talc insufflation appears to cause a marked shift in the pleural milieu from angiogenic to angiostatic.

Angiogenesis is composed of several components, including increases in proliferation of endothelial cells and invasion of the surrounding tissue by new blood vessels [33-35, 37]. The current authors have demonstrated that PF obtained from patients with MPE after thoracoscopic talc insufflation inhibits proliferation of endothelial cells. The decrease in proliferation of HUVEC cells may, in part, be due to the cells undergoing apoptosis [20]. In the present study, there was $21.86 \pm 3.24 \%$ and $31.24 \pm 4.78 \%$ annexin-V FITC binding in the HUVEC pretreated with talc-activated PMC-CM and PF of the patients after $24 \mathrm{~h}$ post thoracoscopy, respectively.

Tumours depend on an invasive vasculature for their growth. Endostatin present in the PF of the talc-insufflated patient is known to modulate this aspect of angiogenesis. To confirm this effect, capillary tube formation and the invasive capacity of endothelial cells was evaluated. The ability of endothelial cells to form a network of tube-like structures on matrigel was significantly disrupted when the cells were co-cultured in PF obtained after $24 \mathrm{~h}$ of talc insufflation. The conditioned media from talc-activated PMC also significantly disrupted the tube formation of endothelial cells. Additionally, inhibition of the invasion of endothelial cells was also noticed. The decreases in tube formation and invasion of endothelial cells could be attributed to the talc-induced production of the anti-angiogenic factor, endostatin. The disruption of tube-length formation of endothelial cells may be due to a decrease in cell number and apoptosis of endothelial cells.

Several reports in the literature suggest that patients who have had successful pleurodesis have improved clinical status and outcomes compared with patients with failure of pleurodesis $[4,24,25,38]$; some patients may live longer than 1 yr. The presence of high levels of endostatin in the post-thoracoscopy $\mathrm{PF}$ and the in vitro data from the present study suggest that the inhibition of angiogenesis in the pleural space may contribute to eventual outcomes in these patients. Angiogenic factors are produced by malignant cells, and VEGF is one of the best described pro-angiogenic factors responsible for the "angiogenic switch". The control of the angiogenic switch relies upon the balance between pro- and anti-angiogenic factors [39, 40]. The current study demonstrates that an angiogenic environment is present in the pleural space in MPE. The amount of endostatin present in talc-untreated MPE is insufficient to tilt the balance. The addition of talc results in an increase in the amount of endostatin released by normal PMC, with a resultant shift in the balance to angiostasis.

Talc is a cheap, safe and effective sclerosant for MPE [3, 9]. The present authors previously reported that talc induces apoptosis of malignant cells in the pleural space [20]. The present study clearly demonstrates a previously unknown property of talc, i.e. its ability to stimulate normal PMC to release endostatin. Controlling angiogenesis in the pleural space is a logical step towards the treatment of MPE. Although clinical trials with endostatin in the treatment of other types of malignancies have not met with expected results, the current authors believe that it definitely has an important role in controlling tumour growth in the pleural space, but do not believe that endostatin alone will be an answer for the treatment of MPE. However, drugs that target angiogenesis in the pleural space could complement traditional chemotherapeutic agents. A multipronged approach, i.e. targeting tumour cells with chemotherapeutic agents, inhibition of angiogenic factors with anti-VEGF 

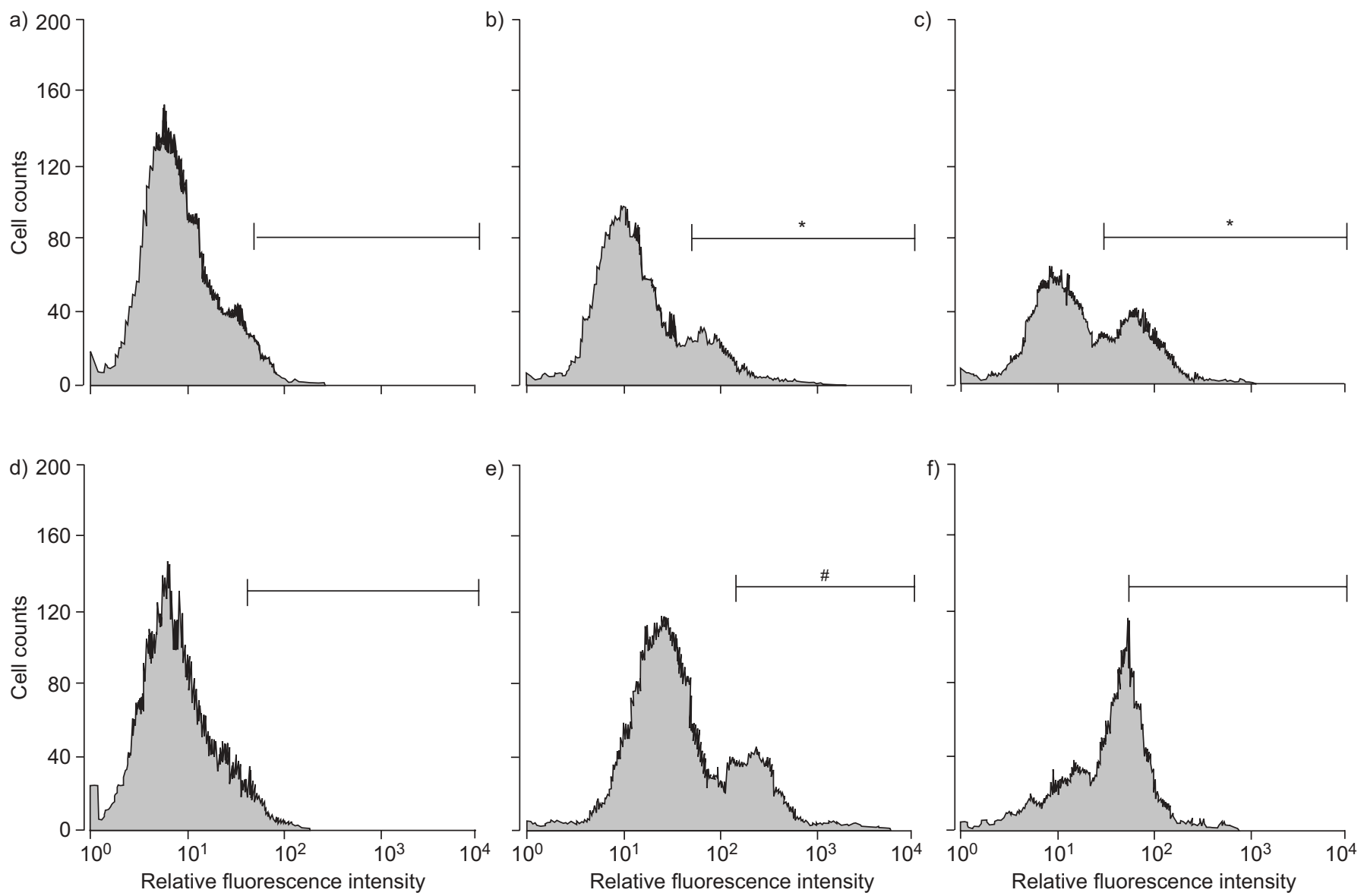

FIGURE 8. Effect of pleural fluid (PF) and pleural mesothelial cell conditioned media (PMC-CM) on annexin-V expression in human umbilical vein endothelial cells (HUVEC). The HUVEC were cultured either in the presence of a) serum-free media, b) PMC-CM, c) talc-activated (25 $\left.\left.\mu \mathrm{g} \cdot \mathrm{cm}^{-2}\right) \mathrm{PMC}, \mathrm{d}\right) \mathrm{PF}$ for $\left.0 \mathrm{~h}, \mathrm{e}\right) \mathrm{PF}$ for $24 \mathrm{~h}$ or f) actinomycin-D. Data presented are representative of three separate experiments. Horizontal bars represent the percentage of apoptosis as follows: a) 2.82 , b) 18.68 , c) 21.86 , d) 7.89 , e) 31.24 , and f) $82.96 .{ }^{*}: \mathrm{p}<0.05$ versus SFM; * : $p<0.05$ versus $0 \mathrm{~h}$ PF.

antibodies and the use of anti-angiogenic factors may have better success.

In conclusion, the findings of the present study support the use of talc as a sclerosing agent in the treatment of patients with recurrent malignant pleural effusions. The environment in the pleural space prior to the administration of talc, as represented by the pleural fluid from patients with malignant pleural effusions, is strongly pro-angiogenic. This microenvironment supports the growth of tumour cells by the presence of angiogenic factors. The insufflation of talc leads to a dramatic and immediate change in the pleural space with a reversal of the angiogenic activity present in the pleural fluid from proangiogenic to angiostatic. The major contributor that moves the biological balance and tips the scale towards angiostasis appears to be endostatin.

\section{REFERENCES}

1 Antony VB, Loddenkemper R, Astoul P, et al. Management of malignant pleural effusions. Eur Respir J 2001; 18: 402-419.

2 Stathopoulos GT, Zhu Z, Everhart MB, et al. Nuclear factorkappaB affects tumour progression in a mouse model of malignant pleural effusion. Am J Respir Cell Mol Biol 2006; 34: $142-150$.

3 Dikensoy O, Light RW. Alternative widely available, inexpensive agents for pleurodesis. Curr Opin Pulm Med 2005; 11: 340-344.

4 Heffner JE, Nietert PJ, Barbieri C. Pleural fluid $\mathrm{pH}$ as a predictor of survival for patients with malignant pleural effusions. Chest 2000; 117: 79-86.

5 Kennedy L, Sahn SA. Talc pleurodesis for the treatment of pneumothorax and pleuraleffusion. Chest 1994; 106: 1215-1222.

6 Kilic D, Akay H, Kavukcu S, et al. Management of recurrent malignant pleural effusion with chemical pleurodesis. Surg Today 2005; 35: 634-638.

7 Mager HJ, Maesen B, Verzijlbergen F, Schramel F. Distribution of talc suspension during treatment of malignant pleural effusion with talc pleurodesis. Lung Cancer 2002; 36: 77-81.

8 Bennett R, Maskell N. Management of malignant pleural effusions. Curr Opin Pulm Med 2005; 11: 296-300.

9 Mourad IA, Abdel Rahman AR, Aziz SA, Saber NM, Fouad FA. Pleurodesis as a palliative treatment of advanced lung cancer with malignant pleural effusion. $J$ Egypt Natl Canc Inst 2004; 16: 188-194. 
10 Walker-Renard PB, Vaughan LM, Sahn SA. Chemical pleurodesis for malignant pleural effusions. Ann Intern Med 1994; 120: 56-64.

11 Kolschmann S, Ballin A, Juergens UR, et al. [Talc pleurodesis in malignant pleural effusions]. Pneumologie 2006; 60: 89-95.

12 Kennedy L, Rusch VW, Strange C, Ginsberg RJ, Sahn SA. Pleurodesis using talc slurry. Chest 1994; 106: 342-346.

13 Kolschmann S, Ballin A, Gillissen A. Clinical efficacy and safety of thoracoscopic talc pleurodesis in malignant pleural effusions. Chest 2005; 128: 1431-1435.

14 Dresler CM, Olak J, Herndon JE 2nd, et al. Phase III intergroup study of talc poudrage vs talc slurry sclerosis for malignant pleural effusion. Chest 2005; 127: 909-915.

15 Viallat JR, Rey F, Astoul P, Boutin C. Thoracoscopic talc poudrage pleurodesis for malignant effusions. A review of 360 cases. Chest 1996; 110: 1387-1393.

16 Nasreen N, Hartman DL, Mohammed KA, Antony VB. Talc-induced expression of $\mathrm{C}-\mathrm{C}$ and $\mathrm{C}-\mathrm{X}-\mathrm{C}$ chemokines and intercellular adhesion molecule- 1 in mesothelial cells. Am J Respir Crit Care Med 1998; 158: 971-978.

17 van den Heuvel MM, Smit HJ, Barbierato SB, Havenith CE, Beelen RH, Postmus PE. Talc-induced inflammation in the pleural cavity. Eur Respir J 1998; 12: 1419-1423.

18 O'Reilly MS, Boehm T, Shing Y, et al. Endostatin: an endogenous inhibitor of angiogenesis and tumour growth. Cell 1997; 88: 277-285.

19 Nasreen N, Mohammed KA, Sanders K, et al. Pleural mesothelial cell (PMC) defense mechanisms against malignancy. Oncol Res 2003; 14: 155-161.

20 Nasreen N, Mohammed KA, Dowling PA, Ward MJ, Galffy G, Antony VB. Talc induces apoptosis in human malignant mesothelioma cells in vitro. Am J Respir Crit Care Med 2000; 161: 595-600.

21 Brunauer S, Emmett PH, Teller E. Adsorption of gases in multimolecular layers. J Am Chem Soc 1938; 60: 306-319.

22 Antony VB, Nasreen N, Mohammed KA, et al. Talc pleurodesis: basic fibroblast growth factor mediates pleural fibrosis. Chest 2004; 126: 1522-1528.

23 Su Y, Cao W, Han Z, Block ER. Cigarette smoke extract inhibits angiogenesis of pulmonary artery endothelial cells: the role of calpain. Am J Physiol Lung Cell Mol Physiol 2004; 287: L794-L800.

24 Aelony Y, Yao JF. Prolonged survival after talc poudrage for malignant pleural mesothelioma: case series. Respirology 2005; 10: 649-655.
25 Hernandez Martnez A, Gomez Izquierdo L, Santiago Villalobos R, Martn Juan J, Castillo Gomez J, Rodriguez Panadero F. CD8+ lymphocyte subpopulations in pleural fluid are associated with longer survival in patients with malignant pleural effusion (MPE) submitted to thoracoscopic talc pleurodesis. Eur Respir J 2002; 20: Suppl. 38, 70s.

26 Sahn SA. Talc should be used for pleurodesis. Am J Respir Crit Care Med 2000; 162: 2023-2024.

27 Light RW. Talc should not be used for pleurodesis. Am J Respir Crit Care Med 2000; 162: 2024-2026.

28 Light RW. Talc for pleurodesis? Chest 2002; 122: 1506-1508.

29 Rinaldo JE, Owens GR, Rogers RM. Adult respiratory distress syndrome following intrapleural instillation of talc. J Thorac Cardiovasc Surg 1983; 85: 523-526.

30 Ferrer J, Villarino MA, Tura JM, Traveria A, Light RW. Talc preparations used for pleurodesis vary markedly from one preparation to another. Chest 2001; 119: 1901-1905.

31 Maskell NA, Lee YC, Gleeson FV, Hedley EL, Pengelly G, Davies RJ. Randomized trials describing lung inflammation after pleurodesis with talc of varying particle size. Am J Respir Crit Care Med 2004; 170: 377-382.

32 Sriram PS, Mohammed KA, Nasreen N, et al. Adherence of ovarian cancer cells induces pleural mesothelial cell (PMC) permeability. Oncol Res 2002; 13: 79-85.

33 Toi M, Hoshina S, Takayanagi T, Tominaga T. Association of vascular endothelial growth factor expression with tumour angiogenesis and with early relapse in primary breast cancer. Jpn J Cancer Res 1994; 85: 1045-1049.

34 Toi M, Tominaga T, Osaki A, Toge T. Role of epidermal growth factor receptor expression in primary breast cancer: results of a biochemical study and an immunocytochemical study. Breast Cancer Res Treat 1994; 29: 51-58.

35 Zetter BR. Angiogenesis and tumour metastasis. Annu Rev Med 1998; 49: 407-424.

36 Ruiz E, Aleman C, Alegre J, et al. Angiogenic factors and angiogenesis inhibitors in exudative pleural effusions. Lung 2005; 183: 185-195.

37 Carmeliet P, Jain RK. Angiogenesis in cancer and other diseases. Nature 2000; 407: 249-257.

38 Sahn SA. Management of malignant pleural effusions. Monaldi Arch Chest Dis 2001; 56: 394-399.

39 Grove CS, Lee YC. Vascular endothelial growth factor: the key mediator in pleural effusion formation. Curr Opin Pulm Med 2002; 8: 294-301.

40 Herbst RS, Onn A, Sandler A. Angiogenesis and lung cancer: prognostic and therapeutic implications. J Clin Oncol 2005; 23: 3243-3256. 